OPEN ACCESS

Edited by:

Wei Deng,

Renmin Hospital of Wuhan University,

China

Reviewed by:

Qing Qing Wu,

Wuhan University, China

Wei Han,

Dongfang Hospital Affiliated to Tongji

University, China

*Correspondence:

Peng $\mathrm{Li}$

lipeng198610@163.com

Kun Zhao

1227621374@qq.com

Specialty section:

This article was submitted to

Stem Cell Research,

a section of the journal

Frontiers in Cell and Developmental

Biology

Received: 27 December 2020 Accepted: 23 March 2021

Published: 29 April 2021

Citation:

Li Y, WU X, Mao Y, LiU C, Wu Y, Tang J, Zhao K and Li P (2021) Nitric

Oxide Alleviated High Salt-Induced Cardiomyocyte Apoptosis and Autophagy Independent of Blood Pressure in Rats.

Front. Cell Dev. Biol. 9:646575. doi: 10.3389/fcell.2021.646575

\section{Nitric Oxide Alleviated High Salt-Induced Cardiomyocyte Apoptosis and Autophagy Independent of Blood Pressure in Rats}

\author{
Yong $\mathrm{Li}^{1}$, Xiaoguang $\mathrm{Wu}^{1}$, Yukang Mao' ${ }^{1}$, Chi Liu' ${ }^{2}$, Yiting $\mathrm{Wu}^{3}$, Junzhe Tang ${ }^{3}$, Kun Zhao ${ }^{1 *}$ \\ and Peng Li ${ }^{1 *}$ \\ ${ }^{1}$ Department of Cardiology, The First Affiliated Hospital of Nanjing Medical University, Nanjing, China, ${ }^{2}$ Department \\ of Cardiology, The Affiliated Hospital of Xuzhou Medical University, Xuzhou, China, ${ }^{3}$ The First School of Clinical Medicine, \\ Nanjing Medical University, Nanjing, China
}

The present study aimed to explore whether high-salt diet (HSD) could cause cardiac damage independent of blood pressure, and whether nitric oxide (NO) could alleviate high-salt-induced cardiomyocyte apoptosis and autophagy in rats. The rats received $8 \% \mathrm{HSD}$ in vivo. H9C2 cells or primary neonatal rat cardiomyocytes (NRCM) were treated with sodium chloride $(\mathrm{NaCl})$ in vitro. The levels of cleaved-caspase 3/caspase 3, cleaved-caspase 8/caspase 8, Bax/BCl2, LC3 II/LC3 I, Beclin-1 and autophagy related 7 (ATG7) were increased in the heart of HSD rats with hypertension (HTN), and in hypertension-prone $(\mathrm{HP})$ and hypertension-resistant $(\mathrm{HR})$ rats. Middle and high doses (50 and $100 \mathrm{mM}$ ) of $\mathrm{NaCl}$ increased the level of cleaved-caspase 3/caspase 3, cleavedcaspase 8/caspase 8, Bax/Bcl2, LC3 II/LC3 I, Beclin-1, and ATG7 in H9C2 cells and NRCM. The endothelial NO synthase (eNOS) level was increased, but p-eNOS level was reduced in the heart of HSD rats and H9C2 cells treated with $100 \mathrm{mM} \mathrm{NaCl}$. The level of NO was reduced in the serum and heart of HSD rats. NO donor sodium nitroprusside (SNP) reversed the increases of cleaved-caspase 3/caspase 3, cleavedcaspase 8/caspase 8, Bax/Bcl2 induced by $\mathrm{NaCl}(100 \mathrm{mM})$ in $\mathrm{H} 9 \mathrm{C} 2$ cells and NRCM. SNP treatment attenuated the increases of cleaved-caspase 3/caspase 3, Bax/Bcl2, LC3 II/LC3 I, Beclin-1, and ATG7 in the heart, but had no effect on the blood pressure of HSD rats with HR. These results demonstrated that HSD enhanced cardiac damage independently of blood pressure. Exogenous NO supplementarity could alleviate the high salt-induced apoptosis and autophagy in cardiomyocytes.

Keywords: high-salt diet, cardiomyocytes, apoptosis, autophagy, nitric oxide, sodium nitroprusside

\section{INTRODUCTION}

Epidemiological studies have verified an association between high salt intake and cardiovascular diseases (Malta et al., 2018; Neupane et al., 2020; Xue et al., 2020). Clinical trials have demonstrated that reduced sodium intake was associated with a decrease in blood pressure, forming the basis for guideline thresholds (Dorsch et al., 2018; Humalda et al., 2020; Xu et al., 2020). Salt sensitivity is 
defined as the association between sodium intake and the increased risk of cardiovascular diseases in certain populations or individuals. Sodium intake may have differing effects on the individual's cardiovascular outcomes like stroke, myocardial infarction, cardiovascular death, and congestive heart failure (O'Donnell et al., 2011; Sadanaga et al., 2019; Welsh et al., 2019).

High salt intake may cause cardiac damage, as indicated by increased cardiac interstitial and perivascular fibrosis, cardiomyocyte size, interventricular septum thickness, and left ventricular (LV) end-diastolic dimension and decreased LV fractional shortening (Komaki et al., 2018). Cardiac apoptosis and fibrosis were found to accelerate in rats with a high-salt diet (HSD) (Chang et al., 2019). High sodium intake increases blood pressure and promotes left ventricular hypertrophy in an independent manner (Le Corvoisier et al., 2010; Cai et al., 2020). However, whether high salt intake can cause cardiac damage independent of blood pressure is not well known.

Enhancing endothelial nitric oxide synthase (eNOS) function by restoring its coupling and subsequently reducing oxidative stress with folic acid may be a novel therapeutic approach to attenuate doxorubicin-induced cardiomyopathy (Octavia et al., 2017). Calcitonin gene-related peptide could protect cardiomyocytes against hypoxia-induced inflammation and apoptosis via nitric oxide (NO)-mediated pathway (Duan et al., 2016). However, whether NO attenuates high salt-induced apoptosis of cardiomyocytes is unclear. This study was to determine the high salt-induced cardiac damage which was independent of blood pressure, and explore whether NO could protect the cardiomyocytes from high salt-induced apoptosis and autophagy independent of blood pressure.

\section{MATERIALS AND METHODS}

\section{Animals}

The experiments were carried out using male Sprague-Dawley (SD) rats weighing 160-180 g (Vital River Biological, Beijing, China). Approved by the Experimental Animal Care and Use Committee of Nanjing Medical University, all procedures were conducted in accordance with the Guide for the Care and Use of Laboratory Animals (NIH publication No. 85-23, revised in 1996). The rats were kept in a temperature-controlled room on a 12-h light-dark cycle with free access to standard chow and tap water. The study was approved by the ethics committee of Nanjing Medical University (No. 2007027)

\section{Rats Fed on HSD}

Male SD rats weighing 160-180 g were randomly assigned to control diet $(\mathrm{CD}, 0.4 \% \mathrm{NaCl})$ group and HSD $(8 \% \mathrm{NaCl}$; Research Diets, NJ, United States) group for 8 weeks. The rats with systolic blood pressure $(\mathrm{SBP}) \geq 150 \mathrm{~mm} \mathrm{Hg}$ were referred as hypertension (HTN) rats, rats with SBP between 130 and $150 \mathrm{~mm} \mathrm{Hg}$ as hypertension-prone (HP) rats, and rats with $\mathrm{SBP}<130 \mathrm{~mm} \mathrm{Hg}$ as hypertension-resistant (HR) rats. Rats were anesthetized with isoflurane $(3.5 \%)$ and killed after a HSD feeding of 8 weeks. The hearts were removed and immediately frozen in liquid nitrogen and stored at $-70^{\circ} \mathrm{C}$ until use.

\section{Measurement of Tail Artery Blood Pressure}

Blood pressure was measured weekly in the tails of conscious rats using a non-invasive computerized tail-cuff system (Kent Scientific, CT, United States). The rats were warmed at $28^{\circ} \mathrm{C}$ for 10-20 $\mathrm{min}$ before the measurement, allowing tail arterial and steady pulsation. To minimize stress-induced fluctuations, the rats were pre-trained to get accustomed to daily blood pressure measurement for at least 1 week. The SBP, diastolic blood pressure (DBP), and mean artery pressure (MAP) of the tail artery were set as the average of at least 10 measurements (Li et al., 2013).

\section{Radiotelemetry Implantation and Data Acquisition}

The rats were implanted with telemetry devices (Data Sciences International, MN, United States) through the abdominal aorta as described previously (Tazumi et al., 2016). Simply, the rats were placed on a heated surgical field in dorsal recumbency under anesthesia with isoflurane (2.5-3.5\%). A midline incision in abdomen was made, and the abdominal aorta was isolated. The rat was implanted with a telemetry device, with the catheter inserted into the abdominal aorta and the transmitter implanted intraperitoneally. Arterial blood pressure was remotely monitored using a commercially available radiotelemetry data acquisition program (Ponemah v6.1; Data Sciences International).

\section{Echocardiography}

Transthoracic echocardiography was performed under isoflurane anesthesia (2.5-3.5\%) using an ultrasound system (Vevo 2100; VisualSonics, Toronto, Canada) with a $21-\mathrm{MHz}$ probe. The ejection fraction (EF) and fractional shortening (FS) of the left ventricular (LV) were calculated. The LV internal diameter at diastolic (LVIDd), LV internal diameter at systolic (LVIDs), LV volumes in diastole (LVVd), LV volumes in systole (LVVs), LV end-diastolic anterior wall thickness (LVAWd), LV end-systolic anterior wall thickness (LVAWs), LV end-diastolic posterior wall thickness (LVPWd), and LV end-systolic posterior wall thickness (LVPWs) were measured. Measurements over three consecutive cardiac cycles were averaged.

\section{Rats Treated With Sodium Nitroprusside}

The $\mathrm{CD}$ rats and $\mathrm{HSD}$ rats with $\mathrm{HR}(\mathrm{SBP}<130 \mathrm{~mm} \mathrm{Hg}$ ) were injected with NO donor sodium nitroprusside (SNP, Sigma, MO, United States). Rat received SNP ( 2.5 or $25 \mu \mathrm{g} / \mathrm{kg}$ ) every 2 days for 2 weeks through the telemetry devices. Then the rats were anesthetized with isoflurane (2.5\%) and killed after receiving SNP for 2 weeks. The hearts were removed, immediately frozen in liquid nitrogen, and stored at $-70^{\circ} \mathrm{C}$.

\section{Culturing of H9C2 Cells}

The rat myoblast cell line H9C2 was cultured in supplemented Dulbecco's Modified Eagle's Medium (DMEM; Biochannel Biotechnology, Nanjing, China) supplemented with $10 \%$ fetal bovine serum (Biochannel Biotechnology), $100 \mathrm{U} / \mathrm{ml}$ of 
penicillin, and $100 \mu \mathrm{g} / \mathrm{ml}$ of streptomycin for $48 \mathrm{~h}$ at $37^{\circ} \mathrm{C}$ in $5 \%$ $\mathrm{CO}_{2}$ and $95 \%$ air.

\section{Grouping of H9C2 Cells}

The H9C2 cells were divided into phosphate-buffered saline (PBS; Biochannel Biotechnology) group, mannitol (100 mM; Sigma, $\mathrm{MO}$, United States) group, and $\mathrm{NaCl}$ groups of three doses $(25,50$, or $100 \mathrm{mM})$ of $\mathrm{NaCl}$. The cells were treated with mannitol or $\mathrm{NaCl}$ for $24 \mathrm{~h}$. In another experiment, the H9C2 cells were divided into PBS, mannitol, $\mathrm{NaCl}$, and $\mathrm{NO}$ donor $\mathrm{SNP}+\mathrm{NaCl}$ groups. All cells were treated for $24 \mathrm{~h}$.

\section{Culturing of Cardiomyocytes Isolated From Neonatal Rats}

Primary cardiomyocytes were isolated from 1- to 2-day-old newborn SD rats (Vital River Biological, Beijing, China). Hearts were excised and digested through agitations in buffer containing collagenase type II (Worthington Biochemical Corporation, NJ, United States) and pancreatin (Sigma). The atria and great vessels were discarded. The ventricles were cut into small pieces and digested with collagenase type II and pancreatin. Cells from digestion were collected, cultured in complete DMEM (Biochannel Biotechnology) for 2-4 h to reduce fibroblasts, and enriched for cardiomyocytes. The cardiomyocytes were cultured at $37^{\circ} \mathrm{C}$ with $5 \% \mathrm{CO}_{2}$ and $95 \%$ air.

\section{Western Blotting}

Left ventricular tissues or cultured cells were sonicated in RIPA lysis buffer and homogenized. The debris was removed and the supernatant was obtained after centrifugation at $12,000 \mathrm{~g}$ for $10 \mathrm{~min}$ at $4^{\circ} \mathrm{C}$. About $30-50 \mu \mathrm{g}$ of proteins was loaded for electrophoresis, and probed with primary antibodies against caspase 3 (1:1000, \#14220; Cell Signaling Technology, MA, United States), cleaved-caspase 3 (1:1000, \#9664; Cell Signaling Technology), caspase 8 (1:1000, \#4790; Cell Signaling Technology), cleaved-caspase 8 (1:1000 \#8592; Cell Signaling Technology), Bax (1:1000, \#5023; Cell Signaling Technology), Bcl2 (1:1000, \#15071; Cell Signaling Technology), LC3 (1:1000, \#12741; Cell Signaling Technology), eNOS (1:1000, \#32027; Cell Signaling Technology), and p-eNOS (Ser1177; 1:1000, abs139915; Absin Bioscience, Shanghai, China) on PVDF membrane. GAPDH (1:1000, AF0006; Beyotime Biotechnology, Shanghai, China) was used as internal control. Images were analyzed using the Image-Pro Plus software.

\section{qRT-PCR}

RNA was isolated from LV tissues or cultured cells using Trizol (Invitrogen). Total RNA $(0.5 \mu \mathrm{g})$ was reversely transcribed into cDNA. qRT-PCR was performed using an ABI Prism 7900 sequencer (Applied Biosystems, Foster City, CA, United States). The primers are shown in Table 1 . The relative level of mRNA expression was expressed as $2^{-\Delta \Delta} \mathrm{Ct}$.

\section{TUNEL Staining}

After treatment, the rate of apoptosis was detected in cells or LV tissues with a One Step TUNEL Apoptosis Assay Kit
(C1089; Beyotime Biotechnology, Wuhan, China) following the manufacturer's instructions. Briefly, having been rinsed with PBS for three times and then fixed with 4\% PFA for $15 \mathrm{~min}$, the heart sections or cells were permeabilized with $0.5 \%$ Triton $\mathrm{X}$ 100 for $5 \mathrm{~min}$. The slides or cells were washed with PBS then incubated with TUNEL reaction mixture containing terminal deoxynucleotidyl transferase (TdT)-mediated cyanine 3 (Cy3)labeled dUTP under humidified atmosphere for $60 \mathrm{~min}$ at $37^{\circ} \mathrm{C}$ in the dark. The negative and positive controls were carried out at the same time. After that, the nuclei were stained with DAPI for $5 \mathrm{~min}$ in the dark. The stained cells or slides were then observed at $570 \mathrm{~nm}$ under a confocal laser scanning microscope (Carl Zeiss, Oberkochen, Germany). Five fields were randomly selected in each slide or wall, and analyzed using ImageJ software in a blinded manner. The number of TUNEL-positive nuclei relative to the total number of nuclei was considered as a surrogate for apoptosis.

\section{Statistical Analyses}

Data were presented as mean \pm SEM. Using GraphPad Prism 7.0 (GraphPad Software, CA, United States), statistical significance among multiple groups was evaluated by one-way ANOVA with the Bonferroni post hoc test. A two-tailed $p$-value $<0.05$ was considered statistically significant.

\section{RESULTS}

\section{Incidence of Non-hypertension and Hypertension}

In 115 HSD-fed rats were 43 Non-HTN rats (37.39\%) and $72 \mathrm{HTN}$ rats (62.61\%). Among the 43 Non-HTN rats, 18 (41.86\%) were HP rats and 25 rats $(58.14 \%)$ had normal blood pressure (Table 2).

\section{Effects of HSD on Body Weight, Food Intake, Blood Pressure, and Cardiac Function}

The body weight of rats in HSD groups with HR, HP, and HTN was less than that in CD group (Figure 1A). Food intake was lower in the three HSD groups than in CD groups (Figure 1B). The SBP, DBP, and MAP in HP and HTN groups were higher than those in CD and HR groups. The SBP, DBP, and MAP in HTN group was higher than those in other three groups (Figure 1). There was no difference in EF and FS between HR, HP, or HTN and CD groups. LVIDd, LVIDs, LVVd, and LVVs were slightly increased in HSD rats with HR, HP, and HTN, but did not show a significant difference. LVAWd, LVAWs, LVPWd, and LVPWs were higher in HSD rats with HR, HP, and HTN than in CD rats (Table 3 ).

\section{Effects of HSD on Apoptosis and Autophagy in the Rat Heart Tissues}

The expression of cleaved-caspase 3/caspase 3 in the heart of HR, HP, and HTN rats fed with HSD was higher than that of $\mathrm{CD}$ rats. The level of cleaved-caspase $8 /$ caspase 8 in the heart of 
TABLE 1 | List of utilized primers for qRT-PCR.

\begin{tabular}{llll}
\hline Gene & Species & Forward primer & Reverse primer \\
\hline Beclin-1 & Rat & $\begin{array}{l}\text { CCATGCAG } \\
\text { GTGAGCTTCGT }\end{array}$ & GAATCTGCGAGA \\
& & GACACCATC \\
ATG7 & Rat & TTCGCCCCC & TGAACTCCAACGT \\
& & GTTCTCAGCCCA & GTGGACGGGT \\
iNOS & Rat & ACAATACAAGA & CGATGTCAC \\
& & AGGTCGGTGTG & TGTAGACCATG \\
GAPDH & Rat & AACGGATTTG & TAGTTGAGGTCA \\
& &
\end{tabular}

TABLE 2 | Incidence of non-hypertension and hypertension of rats with HSD.

\begin{tabular}{lll}
\hline Group & $\boldsymbol{n}$ & $\%$ \\
\hline Total (CD + HSD) & 135 & \\
CD & 20 & 14.81 (\%Total) \\
HSD (HR + HP + HTN) & 115 & 85.19 (\%Total) \\
Non-HTN (HR + HP) & 43 & 31.85 (\%Total), 37.39 (\%HSD) \\
HR & 25 & 18.52 (\%Total), 21.74 (\%HSD), 58.14 \\
HP & 18 & (\%Non-HTN) \\
& & $(\%$ Non-HTN) \\
HTN & 72 & 53.33 (\%Total), 62.61 (\%HSD) \\
\hline
\end{tabular}

$\overline{C D}$, control diet; HSD, high salt diet; HR, hypertension-resistant; HP, hypertensionprone; HTN, hypertension; Non-HTN, non-hypertension.

HR, HP, and HTN rats fed with HSD was increased, compared with that in $\mathrm{CD}$ rats. The expression of $\mathrm{Bax} / \mathrm{Bcl} 2$ in the heart of HR, HP, and HTN rats fed with HSD was significantly elevated. LC3 II/LC3 I expression level was higher in the heart of HR,
HP, and HTN rats. The mRNA levels of Beclin-1 and ATG7 in the heart were increased in the three HSD groups. There were no significant differences in cleaved-caspase 3/caspase 3 , cleaved-caspase 8/caspase 8, Bax/Bcl2, LC3 II/LC3 I, Beclin-1, and ATG7 levels among three HSD groups with HR, HP, and HTN (Figure 2).

\section{Effects of $\mathrm{NaCl}$ on $\mathrm{H} 9 \mathrm{C} 2$ Apoptosis and Autophagy}

Middle $(50 \mathrm{mM})$ and high $(100 \mathrm{mM})$ doses of $\mathrm{NaCl}$ increased the level of cleaved-caspase 3/caspase 3 in H9C2 cells (Figures 3A,B). Middle $(50 \mathrm{mM})$ and high $(100 \mathrm{mM})$ doses of $\mathrm{NaCl}$ increased the levels of cleaved-caspase $8 /$ caspase 8 in H9C2 cells (Figures 3A,C). The expression of $\mathrm{Bax} / \mathrm{Bcl} 2$ was also increased in H9C2 cells by treatment with middle $(50 \mathrm{mM})$ and high (100 mM) doses of $\mathrm{NaCl}$ (Figures 3A,D). LC3 II/LC3 I expression level was elevated in $\mathrm{H} 9 \mathrm{C} 2$ cells by middle $(50 \mathrm{mM})$ and high $(100 \mathrm{mM})$ doses of $\mathrm{NaCl}$ (Figures 3A,E). The mRNA expression levels of Beclin-1 and ATG7 expression were increased in H9C2 cells by treating with middle $(50 \mathrm{mM})$ and high $(100 \mathrm{mM})$ doses of $\mathrm{NaCl}$ (Figures 3F,G). In H9C2 cells, $25 \mathrm{mM} \mathrm{NaCl}$ and mannitol (100 mM) exerted no effect on the levels of cleaved-caspase 3/caspase 3, cleaved-caspase 8/caspase 8, $\mathrm{Bax} / \mathrm{Bcl} 2, \mathrm{LC} 3$ II/LC3 I, Beclin-1, and ATG7 compared with PBS (Figure 3).

\section{Effects of $\mathrm{NaCl}$ on eNOS, p-eNOS, iNOS, and NO Levels}

Middle (50 mM) and high (100 mM) doses of $\mathrm{NaCl}$ increased the level of eNOS in H9C2 cells, while low dose of $\mathrm{NaCl}(25 \mathrm{mM})$ and mannitol $(100 \mathrm{mM})$ had no effect on the levels of eNOS in
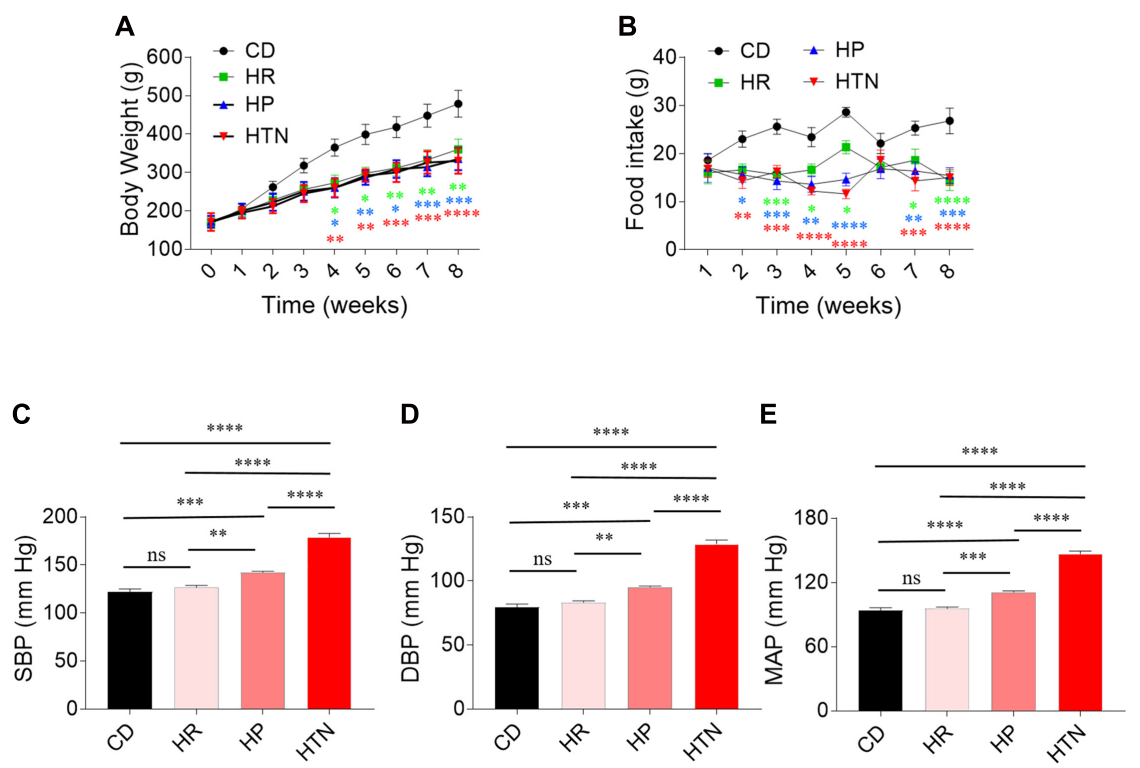

FIGURE 1 | Effects of high-salt diet (HSD) on body weight and blood pressure in rats. (A) The body weight in the HSD groups with hypertension-resistant (HR), hypertension-prone (HP), and hypertension (HTN) was less than that in the control diet (CD) group. (B-D) The SBP, DBP, and MAP in HTN were higher than that in $\mathrm{CD}, \mathrm{HR}$, and HP groups. The results are expressed as mean $\pm \mathrm{SEM} ; n=10$ in CD group, $n=14$ in HR and HP group, and $n=17$ in HTN group. ${ }^{*} p<0.05$, ${ }^{* *} p<0.01,{ }^{* * *} p<0.001$, and ${ }^{* * * *} p<0.0001$. 
TABLE 3 | Cardiac function of rats with CD or HSD.

\begin{tabular}{|c|c|c|c|c|}
\hline Variables & CD & HR & HP & HTN \\
\hline EF (\%) & $72.26 \pm 2.05$ & $70.60 \pm 1.33$ & $69.88 \pm 2.13$ & $69.88 \pm 1.72$ \\
\hline FS (\%) & $42.92 \pm 1.84$ & $41.62 \pm 1.21$ & $41.44 \pm 1.86$ & $41.42 \pm 1.41$ \\
\hline LVIDd (mm) & $7.99 \pm 0.25$ & $8.18 \pm 0.25$ & $8.76 \pm 0.14$ & $8.76 \pm 0.21$ \\
\hline LVIDs (mm) & $4.62 \pm 0.19$ & $4.76 \pm 0.08$ & $5.13 \pm 0.19$ & $5.14 \pm 0.19$ \\
\hline LWd $(\mu l)$ & $345.71 \pm 22.56$ & $384.40 \pm 20.72$ & $422.63 \pm 15.13$ & $424.44 \pm 22.82$ \\
\hline LWs $(\mu l)$ & $112.77 \pm 8.49$ & $115.72 \pm 4.18$ & $127.75 \pm 10.26$ & $128.35 \pm 11.62$ \\
\hline LVAWd (mm) & $1.62 \pm 0.06$ & $2.01 \pm 0.07^{*}$ & $1.86 \pm 0.06^{\star}$ & $1.99 \pm 0.11^{*}$ \\
\hline LVAWs (mm) & $2.86 \pm 0.04$ & $3.35 \pm 0.11^{*}$ & $3.34 \pm 0.14^{*}$ & $3.40 \pm 0.14^{*}$ \\
\hline LVPWd (mm) & $1.68 \pm 0.05$ & $2.20 \pm 0.11^{*}$ & $2.29 \pm 0.09^{*}$ & $2.15 \pm 0.06^{\star}$ \\
\hline LVPWs (mm) & $2.72 \pm 0.06$ & $3.01 \pm 0.12^{*}$ & $3.18 \pm 0.10^{*}$ & $3.16 \pm 0.07^{*}$ \\
\hline
\end{tabular}

CD, control diet; HSD, high salt diet; HR, hypertension-resistant; HP, hypertension-prone; HTN, hypertension. * ${ }^{*}<0.05$ vs. CD group.
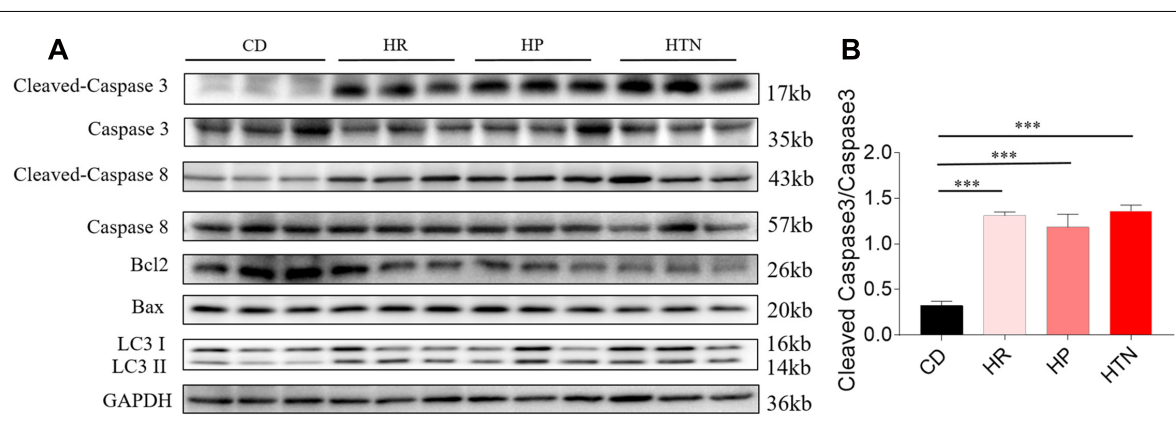

C

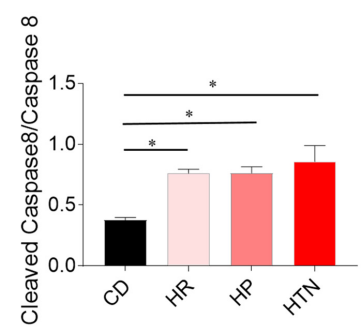

$\mathbf{F}$

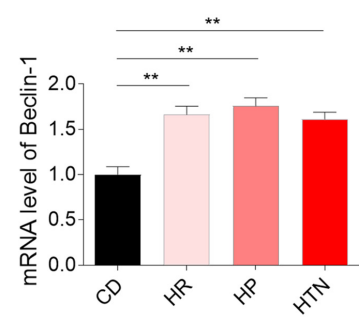

D

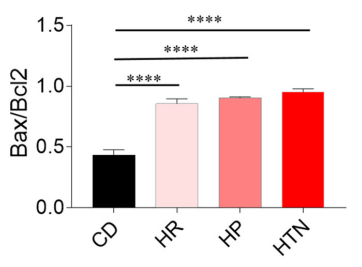

G

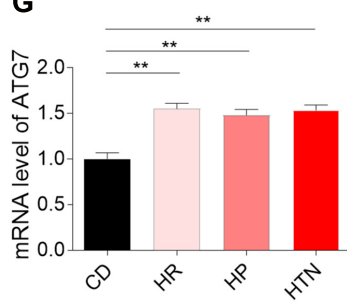

E

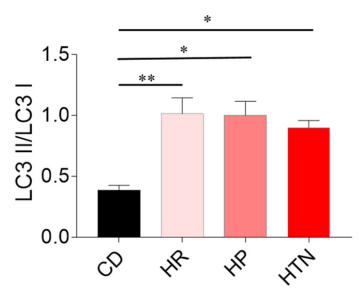

FIGURE 2 | Effects of high-salt diet (HSD) on apoptosis and autophagy in the heart of hypertension-resistant (HR), hypertension-prone (HP), and hypertension (HTN) rats. The expression levels of cleaved-caspase 3/caspase 3 (A,B), cleaved-caspase 8/caspase 8 (A,C), Bax/Bcl2 (A,D), LC3 II/LC3 I (A,E), Beclin-1 (F) and autophagy related 7 (ATG7) (G) were increased in the heart of HSD rats with HR, HP and HTN. The results are expressed as mean \pm SEM; $n=6$ in each group. ${ }^{\star} p<0.05,{ }^{* \star} p<0.01,{ }^{* \star *} p<0.001$, and ${ }^{* \star * *} p<0.0001$.

H9C2 cells. Middle $(50 \mathrm{mM})$ and high $(100 \mathrm{mM})$ doses of $\mathrm{NaCl}$ reduced p-eNOS level in $\mathrm{H} 9 \mathrm{C} 2$ cells (Figure 4A). The level of eNOS was elevated, but p-eNOS level was reduced in the heart of HSD rats with HR compared with the control rats (Figure 4B). Middle $(50 \mathrm{mM})$ and high $(100 \mathrm{mM})$ doses of $\mathrm{NaCl}$ increased the mRNA level of iNOS in $\mathrm{H} 9 \mathrm{C} 2$ cells, while low dose of $\mathrm{NaCl}$
(25 Mm) and mannitol (100 mM) had no effect on the mRNA levels of iNOS in H9C2 cells (Figure 4C). The mRNA level of iNOS was higher in the heart of HSD rats with HR compared with the $\mathrm{CD}$ rats (Figure $4 \mathrm{D}$ ). The level of $\mathrm{NO}$ was lower in the heart of HSD rats with HR compared with the CD rats (Figure 4E). The NO level was reduced in the serum of HSD rats with HR. There 


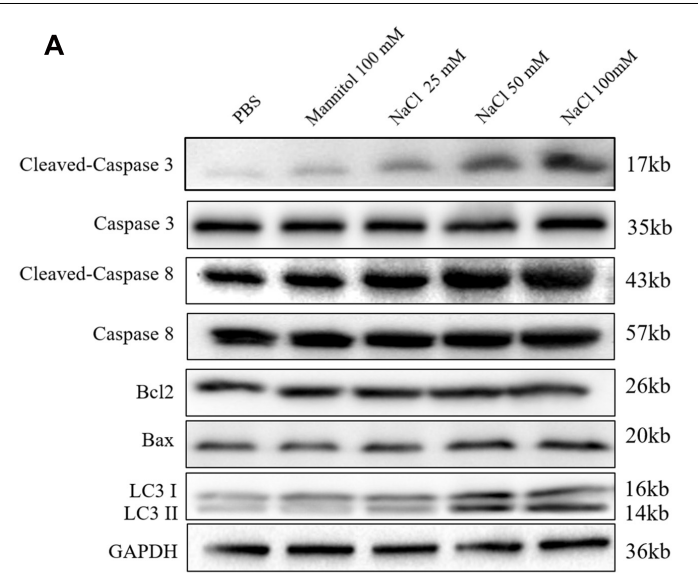

C

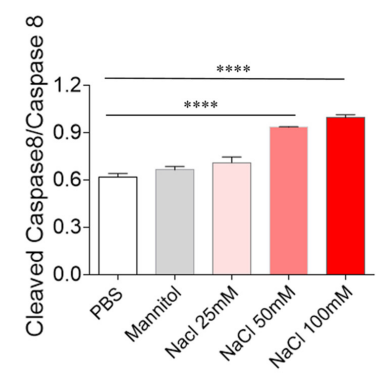

$\mathbf{F}$

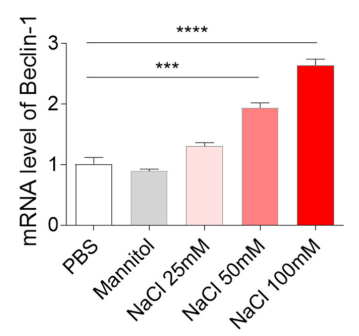

'G
B

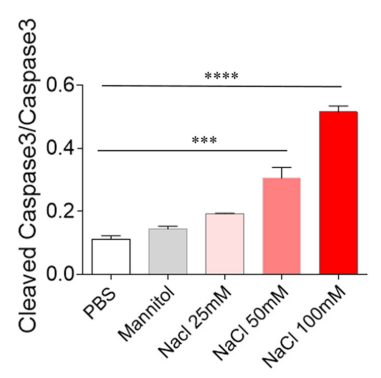

E
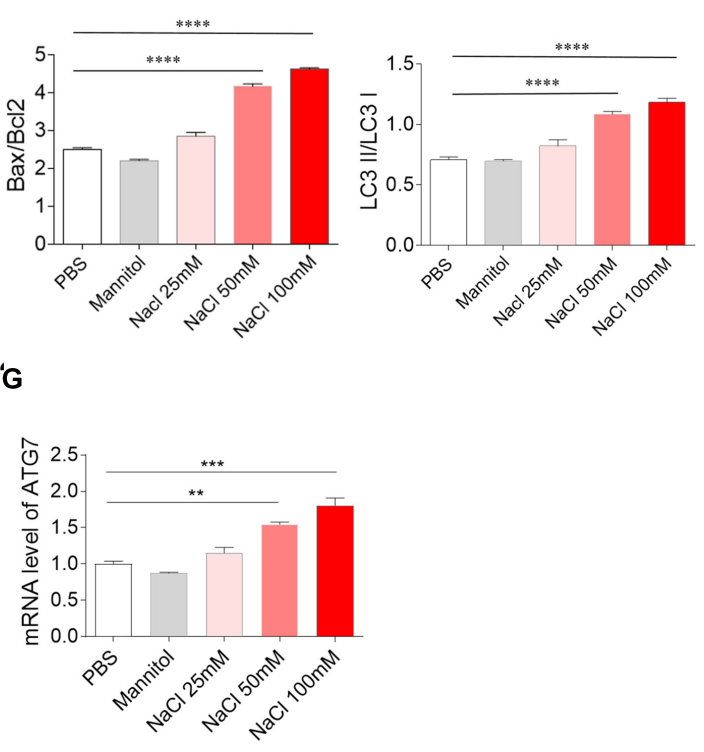

FIGURE 3 | Effects of different doses of sodium chloride ( $\mathrm{NaCl}$ ) on apoptosis and autophagy in $\mathrm{H} 9 \mathrm{C} 2$ cells. Middle $(50 \mathrm{mM})$ and high (100 mM) doses of $\mathrm{NaCl}$ increased the levels of cleaved-caspase 3/caspase $3(\mathbf{A}, \mathbf{B})$, cleaved-caspase 8/caspase 8 (A,C), Bax/Bcl2 (A,D), LC3 II/LC3 I (A,E), Beclin-1 (F), and autophagy related 7 (ATG7) (G) in H9C2 cells. The results are expressed as mean \pm SEM; $n=6$ in each group. ${ }^{* *} p<0.01,{ }^{* \star *} p<0.001$, and ${ }^{* \star * *} p<0.0001$.

was no significant difference in serum NO concentration between HSD rats with HR and CD rats. The NO level in the 24-h urine was reduced in the HSD rats (Figure 4F).

\section{Dose Effects of SNP on NaCl-Induced Apoptosis and Autophagy in $\mathrm{H} 9 \mathrm{C} 2$ Cells}

All the three doses of $\operatorname{SNP}(1,10$, and $100 \mu \mathrm{M})$ attenuated the increases of cleaved-caspase 3/caspase 3 induced by $\mathrm{NaCl}$ (100 mM) in H9C2 cells. SNP $(1 \mu \mathrm{M})$ partly blocked the $\mathrm{NaCl}$-induced increase in cleaved-caspase 3/caspase 3 level in H9C2 cells. Middle $(10 \mu \mathrm{M})$ and high $(100 \mu \mathrm{M})$ doses of SNP completely abolished the $\mathrm{NaCl}$-induced increase in the cleavedcaspase 3/caspase 3 level in H9C2 cells (Figures 5A,B). Middle $(10 \mu \mathrm{M})$ and high $(100 \mu \mathrm{M})$ doses of SNP partly blocked the $\mathrm{NaCl}$-induced increase in cleaved-caspase $8 /$ caspase 8 level in
H9C2 cells, while SNP $(1 \mu \mathrm{M})$ had no effect on the levels of cleaved-caspase 8/caspase 8 in H9C2 cells (Figures 5A,C). SNP $(1 \mu \mathrm{M})$ exerted no effect on the Bax/Bcl 2 level, but SNP $(10 \mu \mathrm{M})$ partly blocked the $\mathrm{NaCl}$-induced increase in the $\mathrm{Bax} / \mathrm{Bcl} 2$ level, and SNP $(100 \mu \mathrm{M})$ completely abolished the NaCl-induced increase in the $\mathrm{Bax} / \mathrm{Bcl} 2$ level in $\mathrm{H} 9 \mathrm{C} 2$ cells (Figures $5 \mathrm{~A}, \mathbf{D}$ ). The increase of LC3 II/LC3 I induced by $\mathrm{NaCl}$ was inhibited by SNP (10 and $100 \mu \mathrm{M}$ ) in H9C2 (Figures 5A,E). The level of eNOS was increased in the $\mathrm{H} 9 \mathrm{C} 2$ cells treated with $\mathrm{NaCl}$ (Figures 5A,F). The level of p-eNOS was reduced in the H9C2 cells treated with $\mathrm{NaCl}$, and this decrease was reversed by SNP $(10$ and $100 \mu \mathrm{M})$ (Figures 5A,G). The mRNA levels of Beclin-1 and ATG7 were increased by $\mathrm{NaCl}$ in $\mathrm{H} 9 \mathrm{C} 2$, and these increases were attenuated by SNP (10 and $100 \mu \mathrm{M}$ ) (Figures 5H,I). The number of positive cells for TUNEL staining was increased in $\mathrm{NaCl}$-treated $\mathrm{H} 9 \mathrm{C} 2$, and this increase was inhibited by high dose 
of SNP $(100 \mu \mathrm{M})$, but not middle $(10 \mu \mathrm{M})$ or low dose $(1 \mu \mathrm{M})$ of SNP (Figure 5J).

\section{Effects of SNP on Three Doses of $\mathrm{NaCl}-$ Induced H9C2 Apoptosis and Autophagy}

In H9C2 cells, SNP $(100 \mu \mathrm{M})$ treatment blocked the increases of cleaved-caspase 3/caspase 3 levels induced by two doses of $\mathrm{NaCl}$ $(50$ and $100 \mathrm{mM})$ (Figures 6A,B). The increased levels of cleavedcaspase $8 /$ caspase 8 induced by $\mathrm{NaCl}(50$ and $100 \mathrm{mM})$ were partly abolished by SNP $(100 \mu \mathrm{M})$ in H9C2 cells (Figures 6A,C). The increases in the $\mathrm{Bax} / \mathrm{Bcl} 2$ level induced by two doses of $\mathrm{NaCl}$ (50 and $100 \mathrm{mM}$ ) were completely blocked by SNP $(100 \mu \mathrm{M})$ treatment in $\mathrm{H} 9 \mathrm{C} 2$ cells (Figures $\mathbf{6 A}, \mathbf{D}$ ). The increase of LC3 II/LC3 I induced by $\mathrm{NaCl}(50$ and $100 \mathrm{mM})$ was inhibited by SNP in H9C2 (Figures 6A,E). The levels of eNOS were increased in the $\mathrm{H} 9 \mathrm{C} 2$ cells treated with $\mathrm{NaCl}(50$ and $100 \mathrm{mM}$ ) (Figures 6A,F). The level of p-eNOS was reduced in $\mathrm{H} 9 \mathrm{C} 2$ cells treated with $\mathrm{NaCl}(50$ and $100 \mathrm{mM})$, and this decrease was reversed by SNP (Figures 6A,G). The increases of Beclin1 and ATG7 induced by $\mathrm{NaCl}(50$ and $100 \mathrm{mM})$ were inhibited by SNP in H9C2 (Figures 6H,I). The numbers of TUNELpositive cells were increased in $\mathrm{H} 9 \mathrm{C} 2$ treated with three doses of $\mathrm{NaCl}$, and these increases were attenuated by SNP $(100 \mu \mathrm{M})$ treatment (Figure 6J).

\section{Effects of SNP on Three Doses of $\mathrm{NaCl}-$ Induced Apoptosis and Autophagy of NRCM}

Sodium nitroprusside $(100 \mu \mathrm{M})$ blocked the increase in cleavedcaspase 3/caspase 3 level induced by two doses of $\mathrm{NaCl}$ (50 and $100 \mathrm{mM}$ ) in NRCM (Figures 7A,B). The increased levels of cleaved-caspase $8 /$ caspase 8 induced by $\mathrm{NaCl}$ (50 and $100 \mathrm{mM})$ were abolished by SNP $(100 \mu \mathrm{M})$ treatment in NRCM (Figures 7A,C). The increases in the $\mathrm{Bax} / \mathrm{Bcl} 2$ level induced by two doses of $\mathrm{NaCl}(50$ and $100 \mathrm{mM})$ were inhibited by SNP $(100 \mu \mathrm{M})$ in NRCM (Figures 7A,D). The expression level of LC3 II/LC3 I was increased in middle and high doses of $\mathrm{NaCl}$-treated NRCM, then reversed by SNP (Figure 7E). The level of eNOS was increased in the NRCM treated with $\mathrm{NaCl}$ (50 and $100 \mathrm{mM}$ ) (Figures 7A,F). The level of p-eNOS was downregulated in $\mathrm{NaCl}$ treated NRCM (50 and $100 \mathrm{mM}$ ), and this decrease was enhanced by SNP (Figures 7A,G). The mRNA levels of Beclin-1 and ATG7 were increased in NRCM treated with three doses of $\mathrm{NaCl}$, and these increases were inhibited by SNP treatment (Figures 7H,I). The numbers of TUNEL-positive cells were increased in NRCM treated with three doses of $\mathrm{NaCl}$, and these increases were attenuated by SNP $(100 \mu \mathrm{M})$ treatment (Figure 7J).

\section{Effects of SNP on Apoptosis and Autophagy in the Heart of HSD Rats}

High-salt diet rats with HR were selected in the next study. HSD increased the levels of cleaved-caspase 3/caspase 3, Bax/Bcl2, and LC3 II/LC3 I in the rat heart. SNP $(2.5 \mu \mathrm{g} / \mathrm{kg})$ had no effects on the increases of cleaved-caspase $3 /$ caspase $3, \mathrm{Bax} / \mathrm{Bcl} 2$, and LC3 II/LC3 I induced by HSD in the rat heart. SNP $(25 \mu \mathrm{g} / \mathrm{kg})$

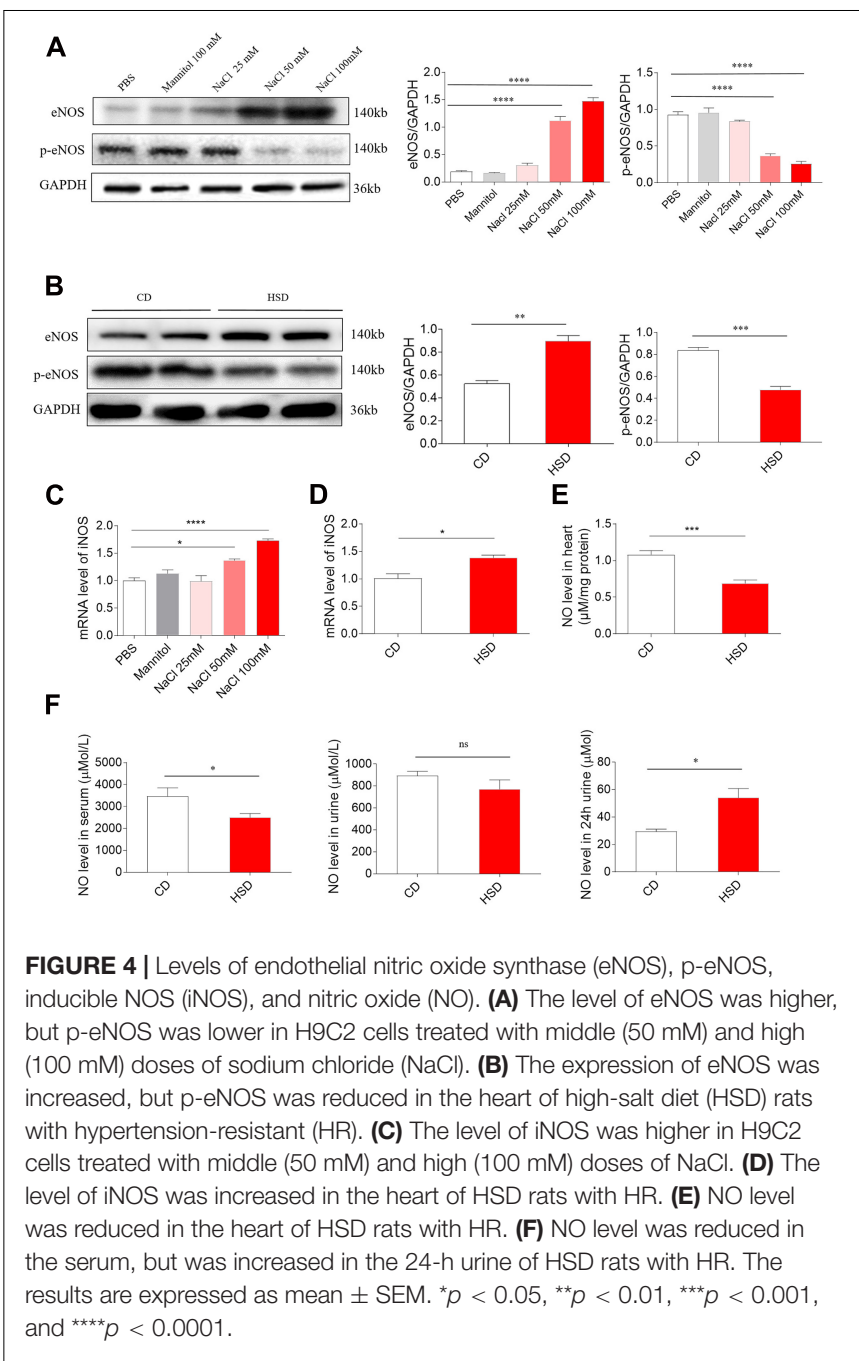

inhibited the increases in cleaved-caspase $3 /$ caspase $3, \mathrm{Bax} / \mathrm{Bcl} 2$, and LC3 II/LC3 I levels in the heart of HSD rats (Figures 8AD). The level of eNOS was increased in the hearts of HSD rats (Figures 8A,E). The decrease of p-eNOS in the hearts of HSD rats was reversed by SNP (2.5 and $25 \mu \mathrm{g} / \mathrm{kg}$ ) (Figures 8A,F). The increases of Beclin-1 and ATG7 m RNA were attenuated by SNP $(25 \mu \mathrm{g} / \mathrm{kg})$ (Figures 8G,H). The number of TUNEL-positive cardiomyocytes was increased in the hearts of HSD rats, and this increase was attenuated by SNP $(25 \mu \mathrm{g} / \mathrm{kg})$ treatment (Figure 8I). NO level was reduced in the heart of HSD rats, then increased by SNP $(25 \mu \mathrm{g} / \mathrm{kg})$ (Figure 8J). SNP had no effect on the blood pressure of HSD rats with HR (Figure 8K).

\section{DISCUSSION}

High-salt diet can aggravate cardiac damage, increase the expression of Bax, enhance the formation of reactive oxygen species, and initiate apoptosis in spontaneously hypertensive rats (Chao et al., 2016). Activating the eNOS/NO signaling cascades can protect from cardiac remodeling in rats after myocardial 

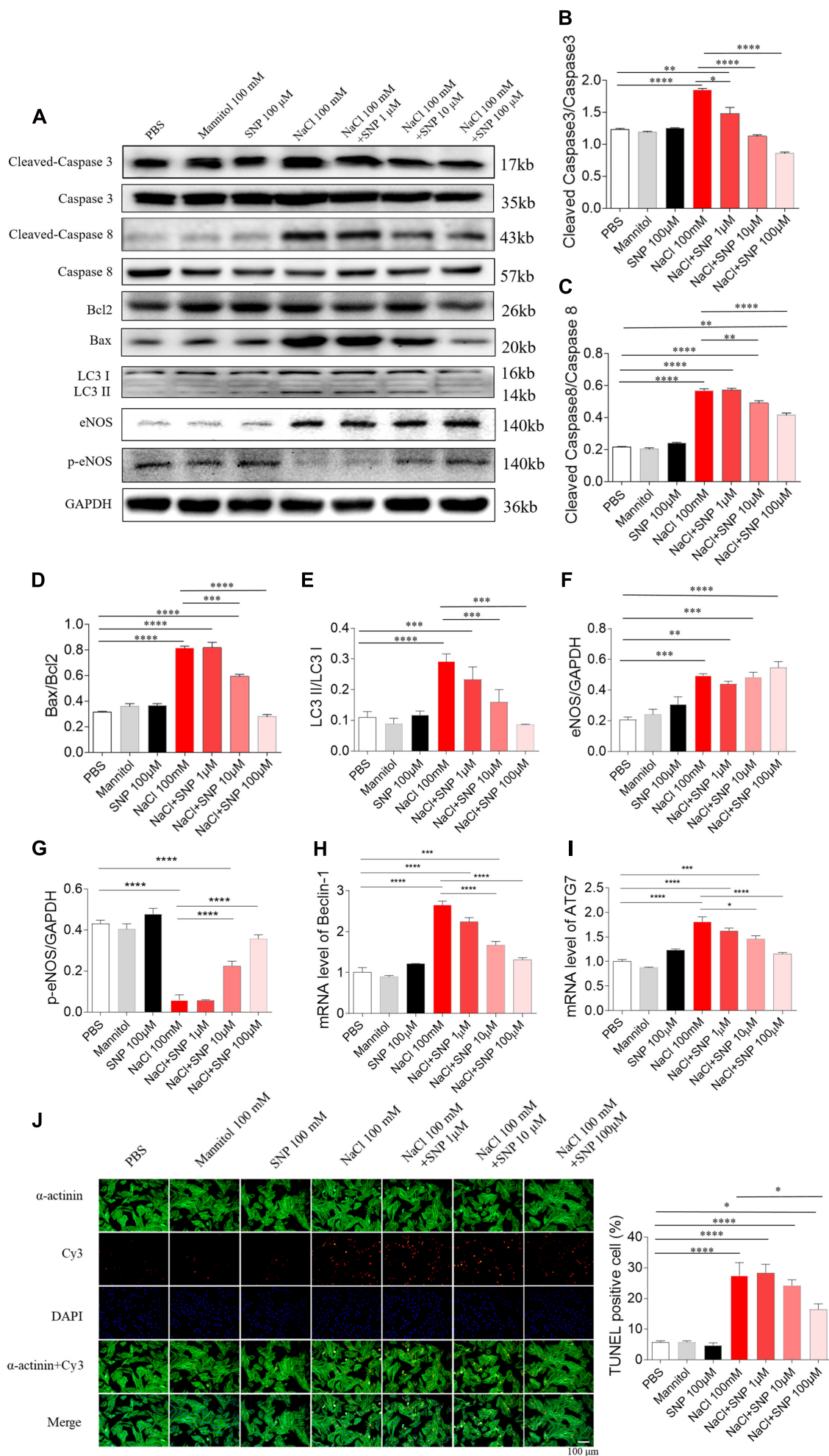

FIGURE 5 | Effects of different doses of nitric oxide donor sodium nitroprusside (SNP) on NaCl-induced apoptosis and autophagy in H9C2 cells. (A-I), SNP attenuated the increases in the levels of cleaved-caspase 3/caspase 3, cleaved-caspase 8/caspase 8, Bax/Bcl2, LC3 I//LC3 I, Beclin-1, and autophagy related 7 (ATG7), and enhanced the decrease of $\mathrm{p}$-endothelial nitric oxide synthase (eNOS) induced by NaCl (100 mM) in H9C2 cells. (J) The increase of TUNEL-positive cell number was inhibited by high dose of SNP $(100 \mu \mathrm{M})$, but not middle $(10 \mu \mathrm{M})$ or low dose $(1 \mu \mathrm{M})$ of SNP. The results are expressed as mean \pm SEM. ${ }^{*} p<0.05$, ${ }^{* *} p<0.01,{ }^{* \star *} p<0.001$, and ${ }^{* \star *} p<0.0001$. 


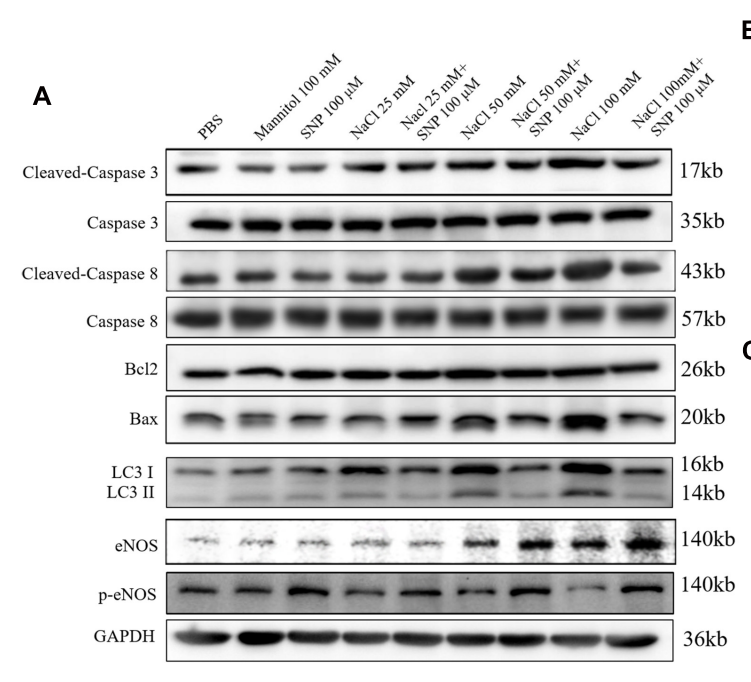

$$
\text { B }
$$

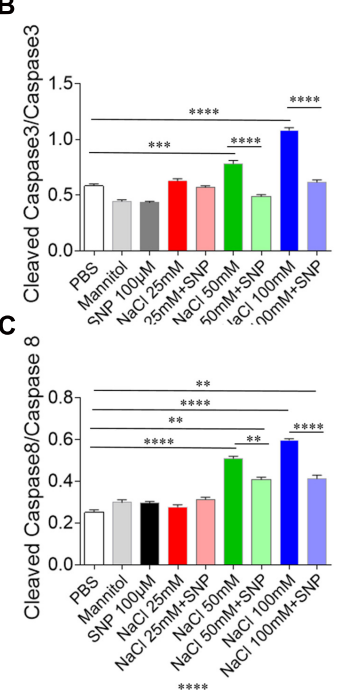

D

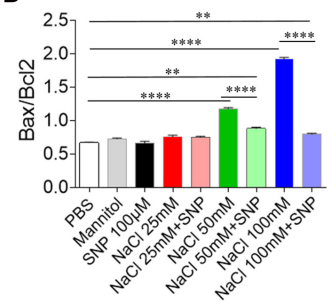

E
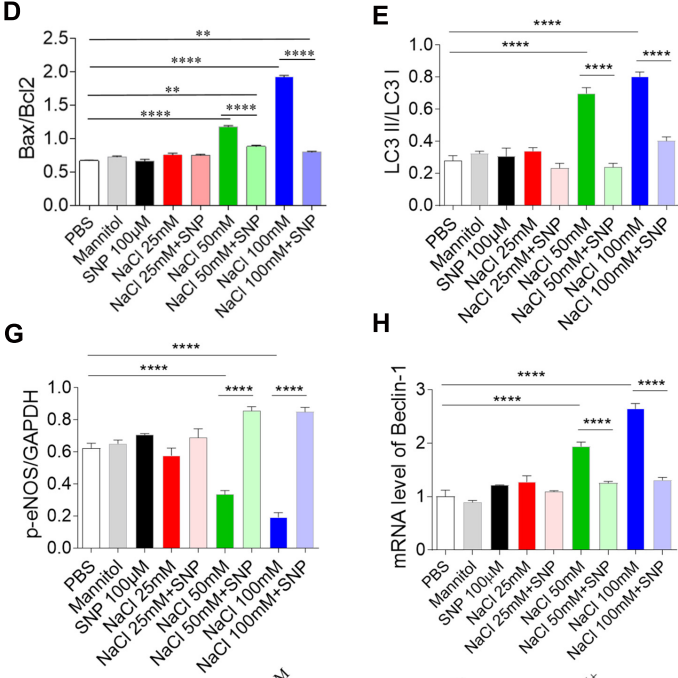

H
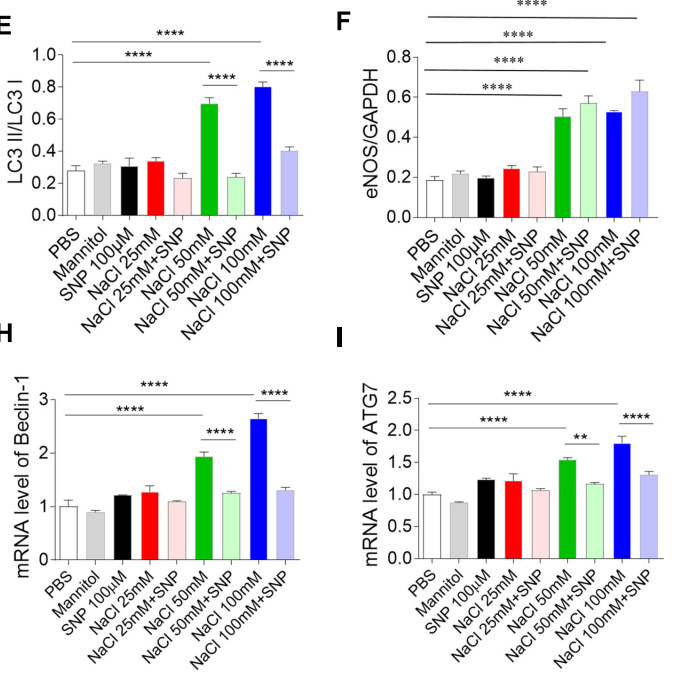

J

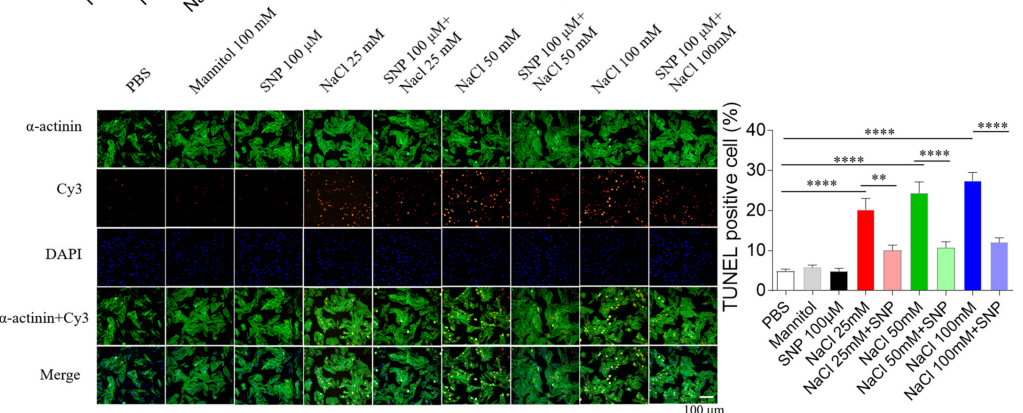

FIGURE 6 | Effects of nitric oxide donor sodium nitroprusside (SNP) on apoptosis and autophagy induced by three doses of sodium chloride (NaCl) in H9C2 cells. (A-I) SNP (100 $\mu \mathrm{M})$ attenuated the increases in the levels of cleaved-caspase 3/caspase 3, cleaved-caspase 8/caspase 8 , and Bax/Bcl2 induced by NaCl (50 or $100 \mathrm{mM}$ ) in H9C2 cells. (F) The increases of TUNEL-positive cell numbers induced by three doses of $\mathrm{NaCl}$ in the $\mathrm{H} 9 \mathrm{C} 2 \mathrm{were}$ attenuated by SNP (100 $\mu \mathrm{M}$ ) treatment. The results are expressed as mean \pm SEM. ${ }^{\star} p<0.05$, ${ }^{\star \star} p<0.01$, ${ }^{\star \star \star} p<0.001$, and ${ }^{\star \star \star \star *} p<0.0001$.

infarction (Li et al., 2017). The present study showed that high salt-induced apoptosis and autophagy in the rat heart and $\mathrm{H} 9 \mathrm{C} 2$ cells could be attenuated by NO donor SNP.

Sudden death is associated with ventricular arrhythmias was observed in Dahl salt-sensitive rats fed with a HSD
(Cho et al., 2018). High-salt intake disrupts the balance between oxidative stress and the antioxidant systems, leading to a higher risk of liver damage, fibrosis, and apoptosis (Wang et al., 2016). In the present study, HSD rats were divided into three groups according to blood pressure, including HR, HP, and HTN. We 


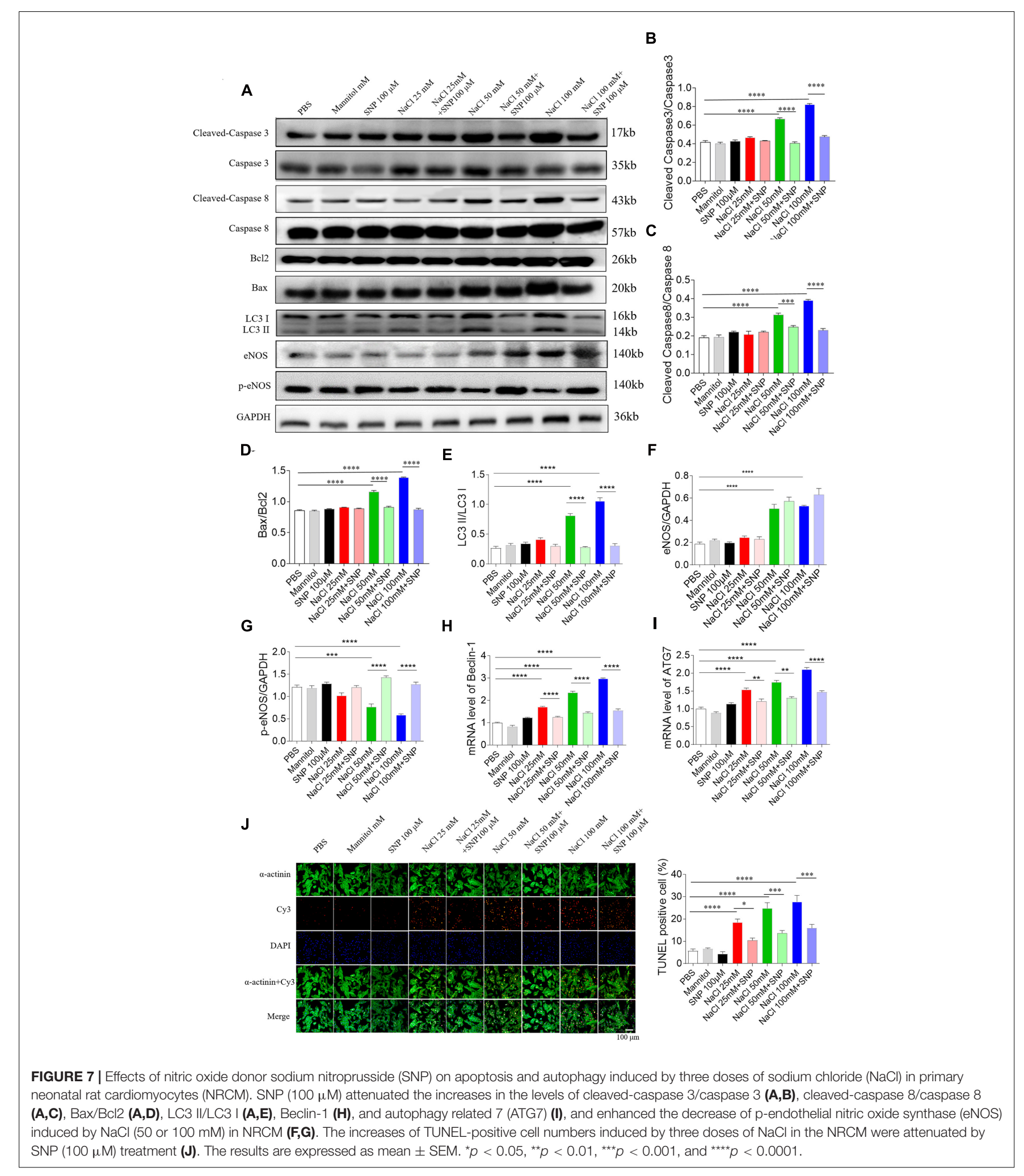

found that the levels of cleaved-caspase 3, cleaved-caspase 8 , and $\mathrm{Bax} / \mathrm{Bcl} 2$ were elevated in the heart of HSD rats with HR, HP, and HTN. Besides, cleaved-caspase 3, cleaved-caspase 8, and Bax/Bcl2 levels were increased in $\mathrm{H} 9 \mathrm{C} 2$ cells treated with high salt. These results demonstrated that high salt promotes the apoptosis of cardiomyocytes independent of blood pressure.

High-level autophagy in the heart impairs cardiac function ( $\mathrm{Li}$ et al., 2018; He et al., 2020). In Dahl rats fed with HSD, their 


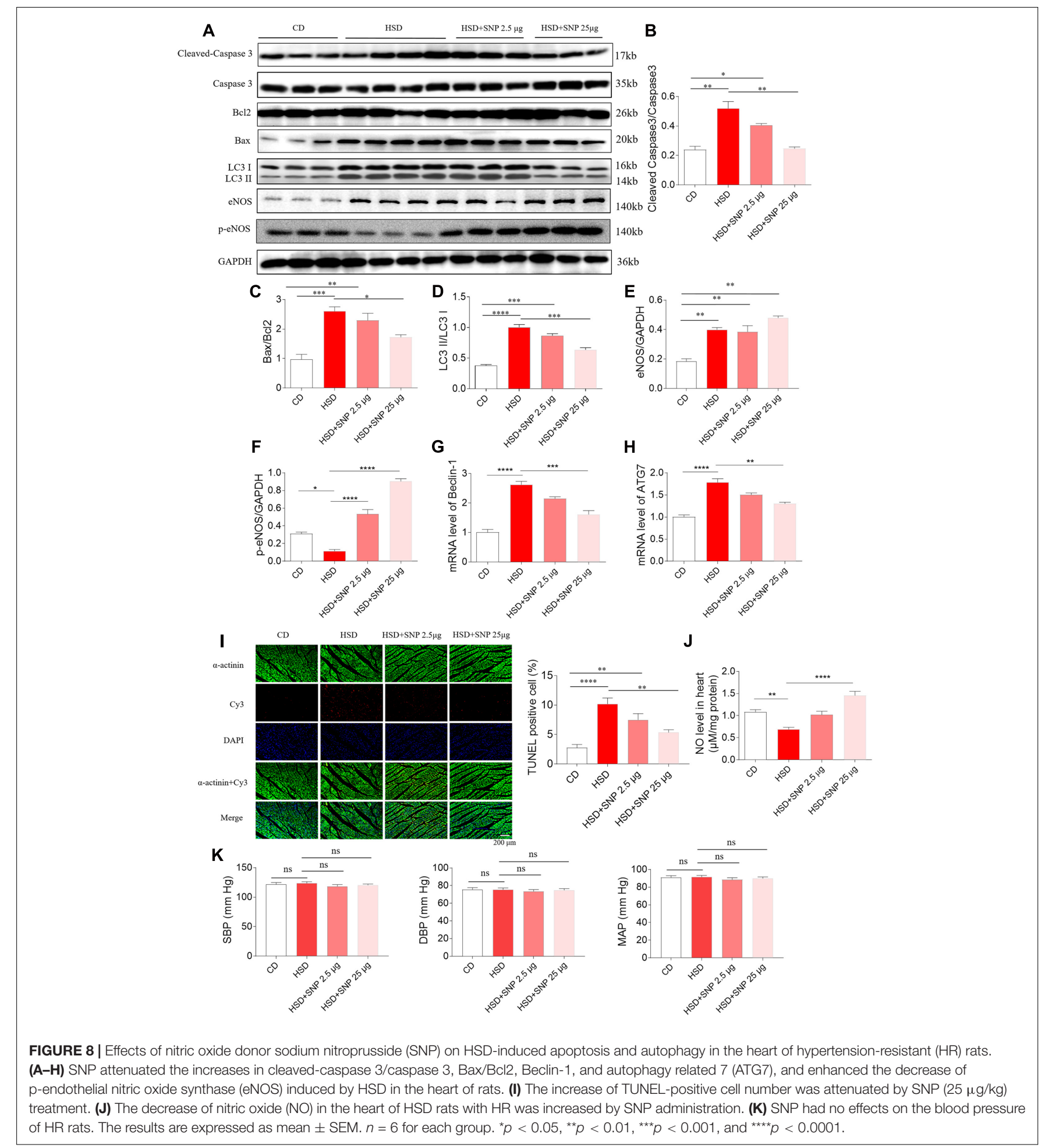

lifespan is shortened by either hypertension-induced stroke or heart failure (Eisenberg et al., 2016). In the present study, LC3 II/LC3 I, Beclin-1, and ATG7 expression levels were higher in the $\mathrm{NaCl}$-treated H9C2 cells. HSD increased the levels of LC3 II/LC3 I, Beclin-1, and ATG7 in the heart of rats with hypertension and non-hypertension. These results indicate that high salt boosts autophagy of cardiomyocytes independent of blood pressure, thus weakening cardiac function and increasing the risk of death.

Nitric oxide induces autophagy with AMP-activated protein kinase and protects the human dental pulp cells against NOinduced apoptosis (Park et al., 2017). The apoptosis is probably enhanced by $\mathrm{NO}$ overproduction and high oxidative stress in 
the heart of cirrhotic rats (Shafaroodi et al., 2017). However, NO can prevent the confluent endothelial monolayer from apoptosis (Lopez-Farre and Rodriguez-Feo, 1998). In the present study, the p-eNOS expression levels were reduced in $\mathrm{NaCl}$-treated $\mathrm{H} 9 \mathrm{C} 2$ cells and the heart of HSD rats. HSD decreased NO level in the serum and heart. NO donor SNP attenuated the increases of cleaved-caspase 3, cleaved-caspase $8, \mathrm{Bax} / \mathrm{Bcl} 2$, LC3 II/LC3 I, Beclin-1, and ATG7 in H9C2 cells induced by NaCl. Furthermore, the HSD-induced increases of cleaved-caspase $3, \mathrm{Bax} / \mathrm{Bcl} 2, \mathrm{LC} 3$ II/LC3 I, Beclin-1, and ATG7 in the heart of rats were suppressed after SNP treatment. These results indicate that eNOS level drops to decrease NO level. HSD decreases NO level to damage the heart, and upregulating eNOS/NO may be a strategy for treating cardiac damage caused by high salt.

The telemetry devices is used worldwide to continuously monitor blood pressure and electrocardiogram (Kiourti et al., 2014; Annoni et al., 2019). In our study, the rats receiving SNP treatment were implanted with telemetry devices in their abdominal aorta. We found that SNP had no effect on the blood pressure of non-hypertensive rats treated with HSD, which is supported by a previous study showing that SNP has no effect on blood pressure of normotensive rats (Hossain et al., 2018). These results indicated that $\mathrm{NO}$ attenuates the high salt-induced apoptosis and autophagy in the heart of HSD rats independently of blood pressure.

In addition to the mechanisms discussed previously, various complex molecular mechanisms, including ion channels, underlying excess salt intake-induced homeostasis imbalance, and subsequent hypertension and even cardiac damage are still not elucidated. Ion channels that present on the plasma membrane and intracellular organelles of all cells have been identified to play an irreplaceable role in regulating cardiac functions through secreting hormones and neurotransmitters, mediating vascular smooth muscle contraction, and supporting cellular integrity (Grant, 2009; Bartos et al., 2015).

Sufficient data confirmed the involvement of the epithelial sodium channel (ENaC), a trimeric ion channel, in the regulation of sodium reabsorption under high-salt intake conditions (Pavlov and Staruschenko, 2017). Diets rich in sodium, in combination with other factors, may harm the normal function of $\mathrm{ENaC}$, contributing to hypertension and even cardiac dysfunction in Dahl salt-sensitive rats (Amin et al., 1979; Greene et al., 1990). Also, endogenous cardiac glycosides released by high-salt intake can inhibit $\mathrm{Na}(+), \mathrm{K}(+)$ ATPase activity, increasing $\mathrm{Na}+$ on the submembrane of vascular smooth muscle cells, which may further facilitate $\mathrm{Ca}^{2+}$ entry and vasoconstriction, and eventually cause a corresponding increase in blood pressure (Iwamoto and Kita, 2006; Jaitovich and Bertorello, 2010). As a vital ion transport determining membrane potential (Iwamoto, 2006b), the $\mathrm{Na}(+) / \mathrm{Ca}(2+)$ exchanger (NCX) type 1 was reported to increase vascular tone by mediating $\mathrm{Ca}^{2+}$ entry in arterial smooth muscle cells in response to excess salt intake, which could partly explain the link between dietary salt to salt-dependent hypertension (Iwamoto et al., 2005; Iwamoto, 2006a). Besides, a HSD could inhibit potassium channels (Oloyo et al., 2013). In addition, recent evidence showed that several transient receptor potential channels (TRP), including TRPV1 and TRPC3, are involved in high-salt intake-induced cardiac hypertrophy by mediating mitochondrial function via regulating mitochondrial calcium uptake (Lang et al., 2015; Ma et al., 2019). Thus, highsalt intake-mediated activation or inactivation of important ion channels in myocytes or vascular muscle cells could also be therapeutically useful for high-salt intake-induced hypertension and cardiac dysfunction, which remains to be further investigated in the future.

High-salt diet-induced hypertension has attracted attention. We currently found that HSD could cause cardiac damage in normotensive rats. This conclusion reminds us to pay close attention to salt intake before developing hypertension. However, the mechanism of high salt in cardiac damage was not well explored in the present study. We only found HSD enhanced apoptosis and autophagy of cardiomyocytes. In the future, we will employ other types of cells to analyze the effect of HSD on cardiac function.

In conclusion, HSD-induced cardiac damage in the heart of rats was independent of blood pressure, and this damage could be attenuated by NO. The eNOS/NO pathway might regulate HSD-induced apoptosis and autophagy in the rat heart.

\section{DATA AVAILABILITY STATEMENT}

The original contributions presented in the study are included in the article/supplementary material, further inquiries can be directed to the corresponding author/s.

\section{ETHICS STATEMENT}

The animal study was reviewed and approved by the Experimental Animal Care and Use Committee of Nanjing Medical University.

\section{AUTHOR CONTRIBUTIONS}

YL designed and performed the experiments and prepared the manuscript. XW, YM, and CL assisted with experiments planning and execution. YW assisted with experiments. JT assisted in project conception and experimental design. KZ and PL designed the experiments, provided the experimental insight, and edited the manuscript. All the authors contributed to the article and approved the submitted version.

\section{FUNDING}

This work was supported by grants from the National Natural Science Foundation of China (No. 81400315) and the Priority Academic Program Development of Jiangsu Higher Education Institutions (No. 10231802). 


\section{REFERENCES}

Amin, M. S., Reza, E., Wang, H., and Leenen, F. H. (1979). Sodium transport in the choroid plexus and salt-sensitive hypertension. Hypertension 2009, 860-867. doi: 10.1161/hypertensionaha.108.125807

Annoni, E. M., Van Helden, D., Guo, Y., Levac, B., Libbus, I., KenKnight, B. H., et al. (2019). Chronic Low-Level Vagus Nerve Stimulation Improves Long-Term Survival in Salt-Sensitive Hypertensive Rats. Front. Physiol. 10:25.

Bartos, D. C., Grandi, E., and Ripplinger, C. M. (2015). Ion Channels in the Heart. Comprehen. Physiol. 5, 1423-1464. doi: 10.1002/cphy.c140069

Cai, W., Lang, M., Jiang, X., Yu, Q., Zhou, C., Zou, W., et al. (2020). Correlation among high salt intake, blood pressure variability, and target organ damage in patients with essential hypertension: Study protocol clinical trial (SPIRIT compliant). Medicine 99:e19548. doi: 10.1097/md.0000000000019548

Chang, R. L., Nithiyanantham, S., Kuo, W. W., Pai, P. Y., Chang, T. T., Lai, C. H., et al. (2019). Overexpression of IGF-IIRalpha regulates cardiac remodeling and aggravates high salt induced apoptosis and fibrosis in transgenic rats. Environ. Toxicol. 34, 210-218. doi: 10.1002/tox.22676

Chao, Z., Liuyang, T., Nan, L., Qi, C., Zhongqi, C., Yang, L., et al. (2016). Mitochondrial tRNA mutation with high-salt stimulation on cardiac damage: underlying mechanism associated with change of Bax and VDAC. Am. J. Physiol. Heart Circ. Physiol. 311, H1248-H1257.

Cho, J. H., Zhang, R., Aynaszyan, S., Holm, K., Goldhaber, J. I., Marban, E., et al. (2018). Ventricular Arrhythmias Underlie Sudden Death in Rats With Heart Failure and Preserved Ejection Fraction. Circ. Arrhythm. Electrophysiol. 11:e06452.

Dorsch, M. P., An, L. C., and Hummel, S. L. A. (2018). Novel Just-inTime Contextual Mobile App Intervention to Reduce Sodium Intake in Hypertension: Protocol and Rationale for a Randomized Controlled Trial (LowSalt4Life Trial). JMIR Res. Protoc. 7:e11282. doi: 10.2196/11282

Duan, L., Lei, H., Zhang, Y., Wan, B., Chang, J., Feng, Q., et al. (2016). Calcitonin Gene-Related Peptide Improves Hypoxia-Induced Inflammation and Apoptosis via Nitric Oxide in H9c2 Cardiomyoblast Cells. Cardiology 133, 44-53. doi: 10.1159/000439123

Eisenberg, T., Abdellatif, M., Schroeder, S., Primessnig, U., Stekovic, S., Pendl, T., et al. (2016). Cardioprotection and lifespan extension by the natural polyamine spermidine. Nat. Med. 22, 1428-1438.

Grant, A. O. (2009). Cardiac ion channels. Circul. Arrhythmia Electrophys. 2, $185-194$.

Greene, A. S., Yu, Z. Y., Roman, R. J., and Cowley, A. W. Jr. (1990). Role of blood volume expansion in Dahl rat model of hypertension. Am. J. Physiol. 258, H508-H514.

He, S., Shen, J., Li, L., Xu, Y., Cao, Y., Yin, L., et al. (2020). Novel Molecular Mechanism of IKKepsilon-Mediated Akt/mTOR Inhibition in the Cardiomyocyte Autophagy after Myocardial Infarction. Oxid Med. Cell Longev. 2020:7046923.

Hossain, E., Sarkar, O., Li, Y., and Anand-Srivastava, M. B. (2018). Inhibition of overexpression of Gialpha proteins and nitroxidative stress contribute to sodium nitroprusside-induced attenuation of high blood pressure in SHR. Physiol. Rep. 6:e13658. doi: 10.14814/phy2.13658

Humalda, J. K., Klaassen, G., de Vries, H., Meuleman, Y., Verschuur, L. C., Straathof, E. J. M., et al. (2020). Self-management Approach for Dietary Sodium Restriction in Patients With CKD: A Randomized Controlled Trial. Am. J. Kidney Dis. 75, 847-856.

Iwamoto, T. (2006a). [Na+/Ca2+ exchanger(NCX1) and salt-sensitive hypertension]. Nihon Rinsho Japan. J. Clin. Med. 64, 167-176.

Iwamoto, T. (2006b). Vascular $\mathrm{Na}+/ \mathrm{Ca} 2+$ exchanger: implications for the pathogenesis and therapy of salt-dependent hypertension. Am. J. Physiol. Regulat. Integr. Compar. Physiol. 290, R536-R545.

Iwamoto, T., and Kita, S. (2006). Hypertension, $\mathrm{Na}+\mathrm{Ca} 2+$ exchanger, and $\mathrm{Na}+$ K+-ATPase. Kidney Internat. 69, 2148-2154. doi: 10.1038/sj.ki.5000421

Iwamoto, T., Kita, S., and Katsuragi, T. (2005). Salt-sensitive hypertension, $\mathrm{Na}+/ \mathrm{Ca} 2+$ exchanger, and vascular smooth muscle. Trends Cardiovasc. Med. 15, 273-277. doi: 10.1016/j.tcm.2005.08.004

Jaitovich, A., and Bertorello, A. M. (2010). Salt, Na+,K+-ATPase and hypertension. Life Sci. 86, 73-78. doi: 10.1016/j.lfs.2009.10.019
Kiourti, A., Psathas, K. A., and Nikita, K. S. (2014). Implantable and ingestible medical devices with wireless telemetry functionalities: a review of current status and challenges. Bioelectromagnetics 35, 1-15. doi: 10.1002/bem.21813

Komaki, H., Iwasa, M., Hayakawa, Y., Okamoto, C., Minatoguchi, S., Yamada, Y., et al. (2018). Azilsartan attenuates cardiac damage caused by high salt intake through the downregulation of the cardiac (pro)renin receptor and its downstream signals in spontaneously hypertensive rats. Hypertens Res. 41, 886-896. doi: 10.1038/s41440-018-0099-0

Lang, H., Li, Q., Yu, H., Li, P., Lu, Z., Xiong, S., et al. (2015). Activation of TRPV1 attenuates high salt-induced cardiac hypertrophy through improvement of mitochondrial function. Br. J. Pharmacol. 172, 5548-5558. doi: 10.1111/bph. 12987

Le Corvoisier, P., Adamy, C., Sambin, L., Crozatier, B., Berdeaux, A., Michel, J. B., et al. (2010). The cardiac renin-angiotensin system is responsible for highsalt diet-induced left ventricular hypertrophy in mice. Eur. J. Heart Fail. 12, 1171-1178. doi: 10.1093/eurjhf/hfq146

Li, F., Zong, J., Zhang, H., Zhang, P., Xu, L., Liang, K., et al. (2017). Orientin Reduces Myocardial Infarction Size via eNOS/NO Signaling and Thus Mitigates Adverse Cardiac Remodeling. Front. Pharmacol. 8:926.

Li, P., Chen, X. R., Xu, F., Liu, C., Li, C., Liu, H., et al. (2018). Alamandine attenuates sepsis-associated cardiac dysfunction via inhibiting MAPKs signaling pathways. Life Sci. 206, 106-116. doi: 10.1016/j.lfs.2018.04.010

Li, P., Sun, H. J., Cui, B. P., Zhou, Y. B., and Han, Y. (2013). Angiotensin-(1-7) in the rostral ventrolateral medulla modulates enhanced cardiac sympathetic afferent reflex and sympathetic activation in renovascular hypertensive rats. Hypertension 61, 820-827. doi: 10.1161/hypertensionaha.111.00191

Lopez-Farre, A., and Rodriguez-Feo, J. A. (1998). Role of nitric oxide in the control of apoptosis in the microvasculature. Intern. J. Biochem. Cell Biol. 30, 1095-1106. doi: 10.1016/s1357-2725(98)00071-5

Ma, T., Lin, S., Wang, B., Wang, Q., Xia, W., Zhang, H., et al. (2019). TRPC3 deficiency attenuates high salt-induced cardiac hypertrophy by alleviating cardiac mitochondrial dysfunction. Biochem. Biophy. Res. Commun. 519, 674681. doi: 10.1016/j.bbrc.2019.09.018

Malta, D., Petersen, K. S., Johnson, C., Trieu, K., Rae, S., Jefferson, K., et al. (2018). High sodium intake increases blood pressure and risk of kidney disease. From the Science of Salt: A regularly updated systematic review of salt and health outcomes (August 2016 to March 2017). J. Clin. Hypertens 20, 1654-1665. doi: $10.1111 /$ jch. 13408

Neupane, D., Rijal, A., Henry, M. E., Kallestrup, P., Koirala, B., McLachlan, C. S., et al. (2020). Mean dietary salt intake in Nepal: A population survey with 24-hour urine collections. J. Clin. Hypertens 22, 273-279. doi: 10.1111/jch. 13813

Octavia, Y., Kararigas, G., de Boer, M., Chrifi, I., Kietadisorn, R., Swinnen, M., et al. (2017). Folic acid reduces doxorubicin-induced cardiomyopathy by modulating endothelial nitric oxide synthase. J. Cell Mol. Med. 21, 3277-3287. doi: 10.1111/ jcmm.13231

O’Donnell, M. J., Yusuf, S., Mente, A., Gao, P., Mann, J. F., Teo, K., et al. (2011). Urinary sodium and potassium excretion and risk of cardiovascular events. JAMA 306, 2229-2238.

Oloyo, A. K., Sofola, O. A., Anigbogu, C. N., Nair, R. R., Vijayakumar, H. S., and Fernandez, A. C. (2013). Testosterone reduces vascular relaxation by altering cyclic adenosine monophosphate pathway and potassium channel activation in male Sprague Dawley rats fed a high-salt diet. Ther. Adv. Cardiovasc. Dis. 7, 75-85. doi: 10.1177/1753944713479996

Park, S. Y., Park, M. Y., Park, H. G., Lee, K. J., Kook, M. S., Kim, W. J., et al. (2017). Nitric oxide-induced autophagy and the activation of activated protein kinase pathway protect against apoptosis in human dental pulp cells. Intern. Endodontic J. 50, 260-270. doi: 10.1111/iej.12616

Pavlov, T. S., and Staruschenko, A. (2017). Involvement of $\mathrm{ENaC}$ in the development of salt-sensitive hypertension. Am. J. Physiol. Renal. Physiol. 313, F135-F140.

Sadanaga, T., Hirota, S., Enomoto, K., Kohsaka, S., Tsujita, K., Ito, M., et al. (2019). Evaluation of sodium intake for the prediction of cardiovascular events in Japanese high-risk patients: the ESPRIT Study. Hypertens Res. 42, 233-240. doi: 10.1038/s41440-018-0149-7

Shafaroodi, H., Hashemi, M., Sharif, Z. N., Moezi, L., Janahmadi, Z., and Dehpour, A. R. (2017). The Possible Role of Nitric Oxide and Oxidative Stress in the 
Enhanced Apoptosis of Cardiac Cells in Cirrhotic Rats. Acta Medica Iranica 55, 29-34. doi: 10.1016/j.niox.2015.11.001

Tazumi, S., Yokota, N., Kawakami, M., Omoto, S., Takamata, A., and Morimoto, K. (2016). Effects of estrogen replacement on stress-induced cardiovascular responses via renin-angiotensin system in ovariectomized rats. Am. J. Physiol. Regul. Integr. Comp. Physiol. 311, R898-R905.

Wang, G., Yeung, C. K., Wong, W. Y., Zhang, N., Wei, Y. F., Zhang, J. L., et al. (2016). Liver Fibrosis Can Be Induced by High Salt Intake through Excess Reactive Oxygen Species (ROS) Production. J. Agricult. Food Chem. 64, 1610-1617. doi: 10.1021/acs.jafc.5b05897

Welsh, C. E., Welsh, P., Jhund, P., Delles, C., Celis-Morales, C., Lewsey, J. D., et al. (2019). Urinary Sodium Excretion, Blood Pressure, and Risk of Future Cardiovascular Disease and Mortality in Subjects Without Prior Cardiovascular Disease. Hypertension 73, 1202-1209. doi: 10.1161/hypertensionaha.119.12726

Xu, A., Ma, J., Guo, X., Wang, L., Wu, J., Zhang, J., et al. (2020). Association of a Province-Wide Intervention With Salt Intake and Hypertension in Shandong
Province, China, 2011-2016. JAMA Intern. Med. 180, 877-886. doi: 10.1001/ jamainternmed.2020.0904

Xue, Y., Wen, Q., Xu, C., Zhang, X., Zeng, J., Sha, A. M., et al. (2020). Elevated Salt Taste Threshold Is Associated with Increased Risk of Coronary Heart Disease. J. Cardiovasc. Transl. Res. 13, 1016-1023 doi: 10.1007/s12265-020-10017-4

Conflict of Interest: The authors declare that the research was conducted in the absence of any commercial or financial relationships that could be construed as a potential conflict of interest.

Copyright $\odot 2021 \mathrm{Li}, \mathrm{Wu}, \mathrm{Mao}, \mathrm{Liu}, \mathrm{Wu}$, Tang, Zhao and Li. This is an open-access article distributed under the terms of the Creative Commons Attribution License (CC BY). The use, distribution or reproduction in other forums is permitted, provided the original author(s) and the copyright owner(s) are credited and that the original publication in this journal is cited, in accordance with accepted academic practice. No use, distribution or reproduction is permitted which does not comply with these terms. 